\title{
An overview about oxidation in clinical practice of skin aging ${ }^{*}$
}

\author{
Silas Arandas Monteiro e Silva ${ }^{1}$ \\ Gislaine Ricci Leonardi ${ }^{3}$ \\ DOI: http://dx.doi.org/10.1590/abd1806-4841.20175481
}

Bozena Michniak-Kohn²

\begin{abstract}
Free radicals are unstable chemical species, highly reactive, being formed by cellular entities of different tissues. Increased production of these species without proper effective action of endogenous and exogenous antioxidant systems, generates a condition of oxidative stress, potentially provider of skin disorders that extend from functional impairments (skin cancer, dermatitis, chronic and acute inflammatory processes) even aesthetic character, with the destruction of structural proteins and cellular changes with the appearance of stains, marks and lines of expressions and other signs inherent to the intrinsic and extrinsic skin aging process. The antioxidants are chemical substances commonly used in clinical practice for topical application and may contribute in the fight against the radical species responsible for many skin damage. This paper summarized the main evidence of the benefits brought by the topical application of antioxidants in the skin, considering the amplitude of the indicative performance of antioxidant activity by in vitro and ex-vivo tests as well as in vivo tests. It is recognized that a breadth of product performance tests should be explored to truly identify the effectiveness of antioxidant products for an anti-aging effect.
\end{abstract}

Keywords: Aging; Antioxidants; Phenolic compounds; Skin aging

\section{INTRODUCTION}

The skin is the largest organ of human body, responsible to cover its entire surface, and has the main function of separating and protecting the inner part of the body from the external environment, in addition to receiving sensory stimulus, helping to regulate the body temperature and excreting undesirable substances. ${ }^{1-9}$

The changes that occur in the skin over time are much more related to the interaction of the skin with the environment than to genetic predisposition. ${ }^{10}$ Therefore, in humans, it can be said that the skin aging is related to personal lifestyle. ${ }^{11,12}$ It is known, for example, that smoking or excessive exposure to solar radiation and low air humidity causes the appearance of wrinkles. In addition, poor diet and excess alcohol intake, as well as some diseases such as diabetes mellitus, significantly accelerate the premature aging of the skin. ${ }^{13,14}$

In the fight against time, people need to arm against two independent processes that accelerate skin aging: chronological or intrinsic, and environmental or extrinsic. In the first, chronological aging signs usually appear around 30 years when the cell renewal work becomes slower and hormone production undergoes changes that reflect directly on the skin. ${ }^{14-18}$

Extrinsic agents are the result of exposure to external elements, especially to UV radiation without protection, that affects the rate of normal skin aging through the formation of free radicals, which attack the skin structures destroying the collagen and elastic fibers, impairing hydration, with consequences such as: dyschromias, changes in skin relief and wrinkles. ${ }^{12,14,15,17,19,20}$

The causal relation observed between oxidative stress and various degenerative processes have aroused the interest for the operation of various antioxidants for application to the skin.

Antioxidants are compounds that inhibit or block the process of formation of free radicals. They must exhibit a redox potential lower than that of the compound that they want to protect, i.e., they must be oxidized first than the protected agent. . $^{21-23}$

The use of antioxidants can also be considered important for maintaining the stability of the formulations. The fragrance and color of a cosmetic product are decisive factors in the product acceptance by consumers. Thus, the protection of lipid oxidation is important, since many products have limited shelf life due to oxidation of the excipients, which may result in alteration of their fragrance and color, for example. ${ }^{21}$

The most common type of oxidation is the lipid, which can occur in oils and fats. Therefore, oils and fats, using catalysts, are transformed into free radicals, which by action of $\mathrm{O}_{2}$ are transformed into peroxides, hydroperoxides, generating breakdown products (rancidity). ${ }^{24}$

\section{Received on 07.12.2015}

Approved by the Advisory Board and accepted for publication on 05.05.2016

* Study conducted at the Postgraduate Program in Translational Medicine of the Federal University of São Paulo (UNIFESP), University of Campinas (UNICAMP) and The State University of New Jersey (RUTGERS), USA.

Financial support: São Paulo State Research Support Foundation (FAPESP/2013-01118-5) and National Council for Scientific and Technological Development (CNPq).

Conflict of interest: None.

Medicine Department - Universidade Federal de São Paulo (UNIFESP) - São Paulo (SP), Brazil.

Department of Pharmaceutics, Rutgers-The State University of New Jersey, Ernest Mario School of Pharmacy - New Jersey, United States of America.

Faculty of Pharmaceutical Sciences, Universidade Estadual de Campinas (UNICAMP) - Campinas (SP), Brazil. 
Interestingly, lipid oxidation cannot be avoided or stopped completely. It can be reduced, such to achieve a significant increase in stability and useful life of the final product. Thus, some antioxidants are used in the formulation to protect the product, while others are used to protect the application site such as skin, scalp and mucous membranes. ${ }^{24}$

In addition, many formulations studies have shown physical instability due to the precipitation of chemical entities when antioxidant-rich extracts are incorporated into vehicles. This observation is often justified by the low solubility of polyphenolic compounds (antioxidants compounds) in water, being recommended its incorporation in vehicles provided with surfactants. ${ }^{25,26}$

According to these assumptions, the use of emulsified formulations proves to be an interesting strategy to ensure the effective performance of antioxidant products for topical use. It is also interesting to note that the location of the antioxidant compound at different phases of the emulsified system may influence the antioxidant performance for different application substrates (skin, scalp). This premise reflects what it is conceived as "Polar Paradox". ${ }^{27}$ According to this view, antioxidant compounds of non-polar character has its optimal activity in emulsions whose continuous phase is aqueous because this way the antioxidant is more likely to migrate to the site of application. ${ }^{28}$

The rheological and physical stability of emulsions can also be influenced by the presence of antioxidant components from the class of phenolic compounds. The mechanism by which this event occurs is not fully elucidated, however, for many formulations is perceived a reduction in system viscosity, reducing its stability. Some authors suggest that the interaction of phenolic compounds with ionic surfactants (Sodium Sulfate Lauryl), through non-covalent bonds, is responsible for the instability of emulsion. ${ }^{29}$

Punctually, some antioxidants may interfere directly in the surface tension between the immiscible phases. Catechins, quercetin, gallic acid and antioxidants are examples of compounds capable of reducing the surface tension of the internal phase droplets of the emulsified formulation. Therefore, such properties will reflect the variation of the system droplet size. In this same scenario, rutin is also reported as an agent capable of promoting the stability of the emulsified medium. This compound shows to be able to adsorb the $\mathrm{O} / \mathrm{W}$ interface acting as a system stabilizer. This phenomenon, however, seems to be $\mathrm{pH}$ dependent, according to Di Mattia et al. (2010). ${ }^{30}$

Finally, it is reported that many antioxidants have been encapsulated in solid entrainment systems (nano and microparticles). In these systems, these actives have solubility properties optimized for the hydrophilic medium, as well as longer preservation of their potential neutralization radical, contributing to longer shelf life of the formulations.

\section{CUTANEOUS ANTIOXIDANT SYSTEMS AND FREE RADI- CALS}

The human body has endogenous defense mechanisms against free radicals, such as enzymatic and non-enzymatic mechanisms of antioxidant activity. Among the enzymatic mechanisms stand out systems superoxide dismutase, catalase, and glutathione peroxidase and from the non-enzymatic there is a large number of compounds synthesized in vivo or obtained exogenously. Among the substances that cause endogenous stress some hormones, such as estradiol and estrogen, have antioxidant activity similar to vitamin E, probably due to its phenolic portion common to both molecules and melatonin.

Lipoic acid is also highlighted by being an essential cofactor in many enzyme complexes, having antioxidant activity and serving as regenerating oxidized forms of glutathione, ascorbate and alpha-tocopherol; as well as melanin, a pigment formed by oxidation and polymerization of tyrosine with protective role against UV radiation. However, as part of the natural aging process, there is a reduction of endogenous defense mechanisms, while there is increased production of reactive oxygen species, resulting in accelerated aging of the skin, i.e., there is an imbalance in the skin redox system, favoring the excessive accumulation of oxidants. ${ }^{31-35}$

Thus, the topical application of antioxidants may represent an attractive strategy for skin protection against oxidative stress caused by different agents. After all, it is intuitive that the topical application of antioxidants can neutralize the free radicals generated in this process, leading to the reduction or prevention of the signs of skin aging and damage caused by ultraviolet radiation and erythema due to inflammation (e.g., post-treatment with chemical or laser peels). ${ }^{36}$

It defines that free radicals are atoms or molecules that have unpaired electrons in its last electronic layer. These agents are extremely reactive and have short-lives, as they react in the proper medium in which are generated. Contrary to popular belief, other reactive molecules such as molecular oxygen, singlet oxygen and hydrogen peroxide are not considered free radicals, but are capable of initiating oxidative reactions and generate free radicals. Together, these species are termed reactive oxygen species (ROS). ROS are inherent in the human metabolism. In addition to the reactive oxygen species, there are the reactive nitrogen species (RNS). ${ }^{37-40}$

Many are the ROS formed in the body, being that in the skin there is formation of large amounts of hydroxyl radicals, superoxide, peroxyl, singlet oxygen and hydrogen peroxide and organic.

The main damage of these reactive species (free radicals) is caused by their reaction with other radicals, with indirect iron-sulfur proteins grouping and by inducing the formation of hydroxyl, by reaction with transition metals such as iron and copper. Hydrogen peroxide is little reactive by itself, but is able to cross membranes and react with transition metals to form the hydroxyl radical. Such a reaction is known as Fenton reaction. ${ }^{33,37,41}$

The hydroxyl radical is the ROS that causes more deleterious effects on the body. Due to its extremely short half-life, it can hardly be captured in vivo. This radical can attack other molecules for capturing hydrogen, react with compounds by adding or transferring its electrons. ${ }^{374}$

Genetic alterations caused by UV exposure involve not only the direct absorption of energy by the DNA molecule, but also the generation of hydroxyl radical from a water molecule. The hydroxyl radical reacts readily with DNA, causing mutations that may induce cancer. ${ }^{33,37}$

It is known that proteins, lipids and DNA molecules are the 
most exposed to oxidative damage. This damage can interfere with their normal function and lead to several pathological processes, such as inflammation and cancer. In proteins, amino acids such as proline, histidine, arginine and cysteine are particularly important because they are susceptible to attack by hydroxyl radicals and oxidative damage. It is known that in this scenario, the oxidation of amino acid residues can lead to fragmentation of the protein, aggregation, and proteolytic digestion. These changes in protein structure do not undergo repair mechanisms, requiring the synthesis of new proteins to replace the damaged. When ROS attack the special class of proteins, enzymes, occurs inactivation of their functions. ${ }^{42,43}$

When oxidation has as main target the biological membranes it settles the phenomenon of lipid peroxidation, also called lipid peroxidation. In this process the ROS attack the double bonds of polyunsaturated fatty acids, responsible for membrane fluidity, causing changes in its constitution and selectivity. ${ }^{43,44}$

Other biological material passively susceptible to the attack of ROS is the nucleic acids. Unlike proteins, when the nucleic bases are attacked by ROS, they can be repaired by complex mechanisms. However, in spite of this possibility of repair, permanent modifications of the genetic material may occur, leading to mutagenesis, carcinogenesis and aging. ${ }^{43,44,45}$

Despite these disastrous effects on cell structures produced by ROS is important to say that when these species are at moderate levels, they undoubtedly produce beneficial effects by promoting the induction of cellular responses against infectious microorganisms and the mitotic response. Therefore, there is a balance between beneficial and harmful effects of free radicals, which is important for human beings. Several factors are involved in this balance, including elements that promote the prevention, repair, physical defense and antioxidant activity. Thus, it is important to recognize the importance of this balance and understand their involvement in skin aging. ${ }^{43,45,46}$

\section{CUTANEOUS REDOX-SYSTEM, SKIN AND AGING}

Few tissues are subject to as much oxidative stress as the skin, mainly by sun exposure and pollution. At the expense of environmental conditions, due to changes in the environment, with great exposure to radiation partially produced by the destruction of the ozone layer and the high levels of pollution, the body has a high demand for antioxidants. The skin is exposed to ROS endogenous and exogenous sources. Therefore, as mentioned above, the redox balance of the skin tissue is promoted through preventive mechanisms of repair, and the physical defenses of the antioxidant system. ${ }^{34,38,47}$

When the skin is exposed to free radicals, to maintain the natural balance of the tissue, it reduces the production of reactive species by suppressing the enzyme activity, which indirectly generates oxygen metabolites. Other molecules aid in the physical protection of the skin, by increasing the stability of membrane, or by molecules that hindering ROS reach their biological targets. Another defense mechanism is the reference molecules. Through the DNA repair mechanism, enzymes may recognize a damaged base, remove it and incorporate a new base. However, the most important defense mechanism is the antioxidant system consisting of enzymes and other non-enzymatic substances. ${ }^{46}$
Studies show that the skin tissue has a varied antioxidant system, ensuring protection against various oxidizing substances. The epidermis and dermis have this defense system, though levels in the epidermis are higher. The main skin antioxidants molecules are ascorbic acid, $\alpha$-tocopherol, glutathione and ubiquinol distributed in different quantities and cell compartments. The low molecular weight antioxidants act in several ways on the skin tissue, either by chelating metallic ions or by direct neutralization of free radicals. ${ }^{24}$

For example, when a reactive species is generated in a lipophilic structure and is reduced by $\alpha$-tocopherol, the regeneration of oxidized $\alpha$-tocopherol by ubiquinol or by ascorbic acid occurs. The dehidroascobato is reduced by glutathione, which in turn is reduced by NAD $(\mathrm{P}) \mathrm{H}$. This balance is critical so the antioxidant system works properly. ${ }^{38,46}$

Aging is a series of irreversible and inevitable physiological changes, accompanied with a change in the normal functioning of the body. Intrinsic aging is characterized by decreased functional capacity, increased susceptibility to certain diseases and environmental stresses and is suffered by all tissues. The most noticeable changes in the skin are flaccidity, fine lines, deepening of wrinkles and dryness. ${ }^{48}$

On the other hand, the so-called extrinsic aging is the result of action of many environmental factors such as chronic sun exposure and pollution. The appearance on the skin may vary between individuals, and is dependent on the level of melanization, of the individual predisposition, frequency and duration of UV exposure throughout life. As a result, there is thickening and drying of skin, formation of deep wrinkles, melanoses, telangiectasias and other benign lesions, premalignant and malignant. It is interesting to note that while intrinsic aging is perceived in the area with some exposure to radiation, the extrinsic is evidently highly exposed, such as the face, neck, arms, forearms and hands. ${ }^{49,50}$

Several studies identify that exposure to sun and extrinsic aging, also called photoaging, increases the risk of cancer development. The sensitivity to sunlight is dependent on skin pigmentation, i.e. individuals with high pigmentation are generally less sensitive than those with clearer skin. ${ }^{51,52}$

It is known that excessive exposure to sunlight and sunburn leads to the emergence of acute injury to the skin. The first obvious answer is inflammation characterized by erythema, edema and blisters, in more severe cases. Erythema is characterized by vasodilation with infiltration in epidermis and dermis of various inflammatory cells such as mastocytes, neutrophils, monocytes and lymphocytes. It also occurs depletion of Langerhans cells that causes a state of immunosuppression. $33,51,53$

UV radiation may be comprised of three bands, according to its propagation characteristics and biological effect. Thus, there is UVC radiation (100-290nm), which hardly reaches the Earth's surface because it is filtered by the ozone layer; UVB (290-320 nm), which has high energy and is responsible for the immediate effects of solar radiation; and UVA (320-400), which induces several cellular changes, with fibroblasts and melanocytes being very susceptible. ${ }^{33}$

It is proven that UV radiation is associated with the onset of skin cancer that is more common among clear skin populations. Three types are associated with sun exposure: basal cell carcinoma 
(BCC), squamous cell carcinoma (SCC) and cutaneous melanoma (CM). BCC and SCC are the result of malignant transformation of keratinocytes, melanocytes and melanoma. ${ }^{53}$

UVB radiation is the most related to the development of SCC. DNA absorbs UVB radiation, leading to multiplication in the transcription of the DNA chains. UVB radiation is responsible for tumor initiation, while UVA generates tumor promotion. Compared to UVB, UVA generates more oxidative stress, being mainly responsible for lipid peroxidation. In addition to causing changes in DNA, UVA radiation is also able to inhibit DNA repair. UVA radiation also affects deeper layers of the skin, while UVB radiation reaches only the epidermis..$^{38,44}$

Direct damages, or damages mediated by ROS, which occur in DNA, trigger cellular responses such as activation of the repair system and enzymes that control the cell cycle. These intermediates and their metabolites may react with cell electrolytes, some of which initiate a cellular signaling process, modifying the gene expression. Regardless of the DNA damage, the imbalance in redox caused by UV radiation can lead to apoptosis mechanism. ${ }^{37}$

The substances capable of absorbing UV radiation are called chromophores and they trigger photochemical reactions. There are several chromophores in skin tissue, such as DNA, melanin and trans-urocanic acid. Most of the radiation absorption by the chromophore occurs at wavelengths shorter than 290nm; this condition may be aggravated due to the increasing destruction of the ozone layer, which filters almost all UVC radiation. The trans-urocanic acid is one of the breakdown products of filaggrin present in high concentrations in the skin. The absorption of radiation by trans-urocanic acid molecule causes the formation of singlet oxygen that can attack cell membranes and generate other ROS..$^{37,53}$

Some studies show increased expression of nitric oxide synthase exposed to UVB radiation, resulting in excessive formation of nitric oxide, which stimulates melanocytes to produce melanin. In addition, nitric oxide can also react with superoxide to form peroxynitrite anion, which is highly reactive. ${ }^{33}$

Ultraviolet radiation induces expression of a number of metalloproteinases (MMP). These enzymes are capable of degrading the collagen structures. Inhibition of procollagen synthesis also occurs, probably via mechanism associated with collagen degradation. Thus, pro-collagen I protein levels are decreased whereas the activity of MMP-1 and MMP-2 are increased in skin exposed to radiation, compared with unexposed skin. Such changes possibly occur due to induction of transcription factor activation protein, which is activated by protein-kinases. NF-kB transcription factor is also activated by UV radiation. This factor is an agent that is activated by oxidative stress and acts stimulating multiple genes related to the pro-inflammatory response. . $^{38,52,54}$

Montagner and Costa $(2009)^{55}$ describe that the reactive oxygen products, formed by ultraviolet radiation, lead to increase of collagen degradation and decreased of collagen synthesis. Figure 1 illustrates the molecular responses to solar aggression.

So, the theory that free radicals are involved in skin aging process has been studied. The accumulation of oxidative reactions products may be involved in the aging process. Many enzymes are activated when the skin is exposed to UV radiation, indirectly lead- ing to the production of ROS, which generate oxidative stress. The quantification of antioxidant molecules demonstrated a decrease of these molecules in aged skin, suggesting the occurrence of a decrease in the antioxidant system.

Thus, the topical application of antioxidants has been prescribed in dermatology clinics and has been desired in cosmetic formulations. However, for topical administration of antioxidants to be effective in the prevention and elimination of free radicals it is critical to ensure the stability of the final formulation, since the antioxidant, in most cases, are very unstable and may be oxidized easily, becoming inactive before reaching the site of action. In addition, antioxidants must be properly absorbed through the skin to reach deeper layers of the tissue in the active form and remain there long enough to provide the desired effects. ${ }^{56}$

Thereby, obtaining formulation added with stable antioxidant, with adequate skin permeation, may cause protection against free radicals and may help grow old with an aesthetically better and healthier skin, resulting in a higher self-esteem and consequently better quality of life with over the years. In addition, the pharmaceutical, in particular dermatological area, has sought constantly antioxidants to be topically applied for the prevention and treatment of a variety of skin problems, especially those caused by UV radiation in short and long term, such as skin cancer. Natural antioxidants are promising in the prevention of skin cancer, as many have shown their anticarcinogenic and antimutagenic effects and low toxicity. Therefore, the use of antioxidants, orally or topically, may help endogenous systems of skin protection, and contribute to preventing problems in the long term. . $33,56,57^{-1}$

The growing interest in natural antioxidants from plant extracts is due to its low toxicity compared with synthetic. ${ }^{58}$ Synthetic compounds such as BHT (butylated hydroxytoluene) and BHA (butylated hydroxyanisole) are effective antioxidants and used in medicines, cosmetics and even food, but may exhibit mutagenic activity. ${ }^{59,60}$

Denham Harman, cited for Wickens, postulated that the aging was related to the formation of free radicals induced by the irradiation in humans. According to this premise, free radicals would be responsible for causing small cell damage that culminated in skin aging. The radical species from different sources (exposure to radiation, chemical inducers, physical injuries) are responsible for causing damage to the DNA and the protein glycation. This latter process is responsible for promoting the loss of the biological function of major structural proteins such as collagen and proteoglycans, contributing to increased skin sagging. ${ }^{61}$ The Figure 2 illustrates the factors involved with skin aging and oxidative stress.

Free radicals can originate from endogenous sources such as mitochondrial oxidation reactions, phagocytosis during the process of inflammation, and through the activation of arachidonic acid metabolism. As exogenous sources of free radicals, we can mention the UV radiation, especially UVA, exposure to pesticides, pollution, cigarette smoke and antitumor drugs. ${ }^{61,62}$

Endogenously, the oxygen molecule is the primary source of free radicals. Oxygen participates in the transport chain of electrons in the mitochondria, being reduced by cytochrome oxidase in water and causing the oxidation of NADH to NAD + molecule, culminating in the formation of ATP. It is known that in the com- 
plete reduction of one molecule of oxygen, about $1 \%$ to $2 \%$ of the electrons are dissipated during transport in the mitochondrial cristae, leading to the formation of superoxide and, consequently, other reactive species such as hydrogen peroxide $(\mathrm{H} 2 \mathrm{O} 2)$ and hydroxyl radicals $(\mathrm{OH}) .{ }^{61-64}$

It is interesting to mention that mitochondrial dysfunctions characterized by enzyme deficiency is responsible for producing excessive amounts of free radicals in the cytoplasm and nucleus and expose the structural components to oxidative stress. This oxidative stress cellular energy machinery with their lipid constitution is the

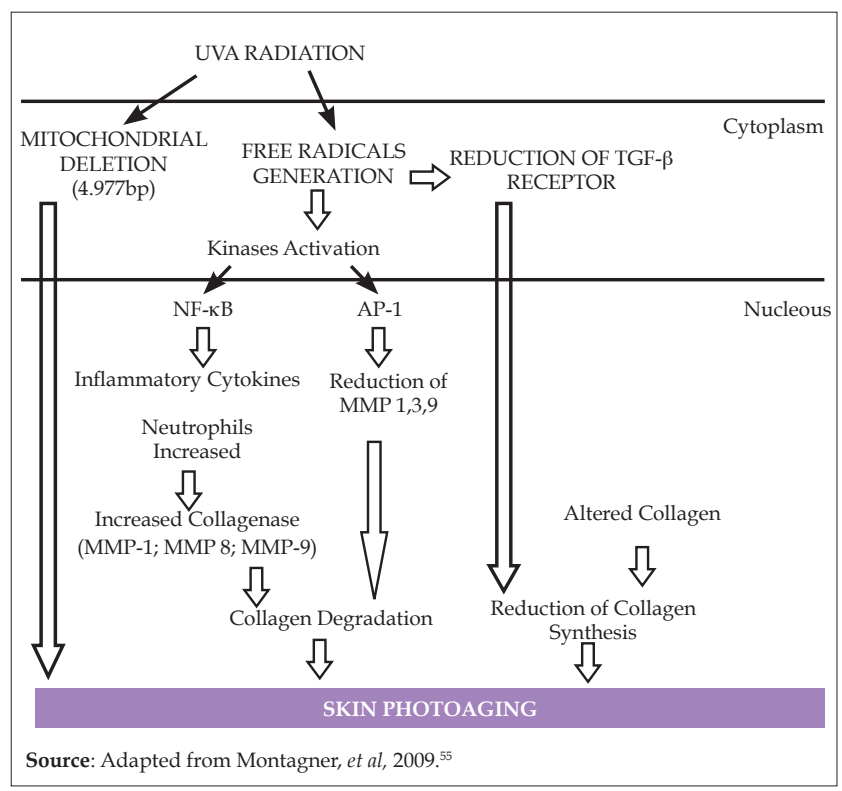

FigURE 1: ROS generation by UVA radiation, producing, in the last instance, the photoaging

\begin{tabular}{|c|c|}
\hline $\begin{array}{l}\text { Exogenous Factors } \\
\text { - UV Radiation; } \\
\text { - Pesticides; } \\
\text { - Pollution; } \\
\text { - Cigarette Smoke; } \\
\text { - Antitumor drugs. } \\
\text { - Physical injuries }\end{array}$ & $\begin{array}{l}\text { Endogenous Factors } \\
\text { - Mitochondrial oxidation; } \\
\text { - Phagocytosis during the } \\
\text { process of inflammation; } \\
\text { - Inflammation and } \\
\text { activation of arachidonic } \\
\text { acid metabolism. }\end{array}$ \\
\hline AGING SKIN & $\begin{array}{ll}\text { s Antioxidant Performance } \\
\qquad & \\
\text { In vitro Tests } & \text { In vivo Tests } \\
\text { - DPPH Test; } & \text { - Lipid peroxidarion } \\
\text { - ABTS Methodology; } \Rightarrow \begin{array}{l}\text { of stratum corneum; } \\
\text { - Clinical trials (Photo- } \\
\text { - ORAC Tesr; } \\
\text { - FRAP Test; }\end{array} & \text { protective); } \\
\text { - } \beta \text {-Carotene; } & \end{array}$ \\
\hline $\begin{array}{l}\text { Scree } \\
\text { more }\end{array}$ & $\begin{array}{l}\text { tests. The oxidant performance should evaluate } \\
\text { one in vitro methodology }\end{array}$ \\
\hline
\end{tabular}

FIGURE 2: Illustration of aspects that could be associate d with oxidative stress and skin aging process, and in vitro / in vivo methodologies that could investigate the antioxidant efficacy most susceptible to free radical attack, with progressive reduction of cellular energy production capacity. The energy depletion leads to tissue degeneration. ${ }^{62}$

Other enzymatic processes responsible for radical production are: conversion of xanthine to uric acid by xanthine oxidase, producing nitric oxide by the enzyme nitric oxide synthase directly to the skin. Injury as ischemic processes and post-ischemic also generates an oxidative stress condition. ${ }^{64}$

In the inflammatory processes the radical species come mainly from neutrophils, eosinophils and macrophages that release $\mathrm{O}_{2}$, converging in the formation of $\mathrm{H}_{2} \mathrm{O}_{2}{ }^{64}$

Photoaging is primarily responsible for skin aging. UVA and UVB radiation interact with intracellular chromophores and photosensitizing agents, generating oxidative stress and transient genetic alterations. ${ }^{62}$

Cell membranes are the main cellular constituents susceptible to oxidation procedure being established, which is known as lipid peroxidation. Amino acid residues are highly susceptible to free radical attack. In addition, DNA also possesses a highly reactive structure with the radical species. .2, $^{2} 5$

\section{USE OF ANTIOXIDANTS PRODUCTS: A BENEFICIAL SEARCH FOR THE SKIN}

Phenolic compounds are formed in the secondary metabolism of plants and have defense functions against pest attack. In animals and humans it has been observed that they are capable of reacting with free radicals to form stable chemical species. ${ }^{59}$ This power of neutralizing the radical structures is due to its chemical structure, which has hydroxyl groups and aromatic rings, in the simplest forms, or polymers that confer antioxidant power. Chemically, the phenolic compounds are defined as substances that have aromatic rings with one or more hydroxyl substituents, including its functional groups. They have variable structure and thus are multifunctional. There are about five thousand phenols, among which we highlight the flavonoids, phenolic acids, simple phenols, coumarins, tannins, lignins and tocopherols. Such compounds can be natural or synthetic. When present in vegetables they can be free or complexed forms as sugars and proteins. ${ }^{66-68}$

Monteiro e Silva \& Leonardi $(2013)^{23}$ found that gallic acid as well as the association of gallic acid, ferulic and caffeic is interesting compounds to be used in topical formulations, showing good antioxidant capacity in vitro and good stability in the formulation.

Besides these features, numerous in vitro and in vivo tests are extensively exploited, characterizing the potential of antioxidants and the products provided of these compounds in order to ensure the delivery of numerous benefits to skin.

\section{POTENTIAL BENEFITS FOR SKIN PROVEN BY IN VITRO TESTS}

In an investigational study, Thring et al. (2011) ${ }^{69}$ demonstrated the antioxidant potential associated with anti-collagenase and anti-elastase activity of 21 plant extracts, showing correlation between the antioxidant power and enzyme inhibitory activity. In this same investigational line Lee et al. (2001) ${ }^{70}$ demonstrated by in vitro assays, inhibitory action of elastase and hyaluronidase, rein- 
forcing potential application of this vegetable resource for anti-aging purposes.

Thus, plant extracts provided with phenolic compounds demonstrate the ability to promote the enzymatic inhibition of specific proteinases such as collagenase and elastase. These, in turn, when activated, are responsible for promoting the degradation of important structural fibers, such as collagen and elastin. It is worth noting that the accumulation of free radicals in the skin is considered an inducing agent for collagenase (MMP-1) and elastase expression, accelerating dermal disruption early. ${ }^{58}$

Test with cell culture of human fibroblasts showed anti-elastase and anti-collagenase action, being the substances such as floretin, 3-hydro-floretin and quercetin, the main responsible for the potential benefit. Kim et al. (2013) $)^{71}$ in their study concluded that aldehydes polycondensates of catechins are most effective for inhibiting metalloproteinases (collagenase and elastase) that the monomers of the same chemical specimen. Such substances are present in plant extracts like green tea (Cammelia sinensis) and uva ursi (Arctostaphylos uva-ursi).

Stevanato (2014) $)^{72}$ demonstrated photoprotective effect of polyphenolic compounds. In his work, the author lists variable rates of protection, with SPF 2-30. These findings reinforce the viability of consideration of use of ingredients rich in these substances to ensure photoprotective action of topical products.

Ruszova et al. (2013) ${ }^{73}$ showed, by in vitro assays, beneficial effect of Epilobium angustifolium extract, after exposure, through downregulation of expression of MMP-1 genes and MMP-3 (collagenases) and hyaluronidase-2. Considering keratinocytes cell lines it is possible to recognize the properties of antioxidants in reducing the formation of free radicals after UVB radiation or induced by hydrogen peroxide in cell cultures (HaCat). Furthermore, the phenolic extracts also show the potential protective action of cellular nucleus, by minimizing the formation of cyclobutane pyrimidine dimers, as well as reducing cellular apoptosis.

Extracts rich in flavonoids and anthocyanins had their protective cellular action recognized against oxidative stress chemically induced in fibroblasts culture. The authors demonstrate that prior treatment of dermal fibroblasts with vegetable extracts rich in antioxidants is responsible for reducing the amount of free radicals and lipid peroxidation and DNA damage. ${ }^{74}$

\section{CONVENTIONAL IN VITRO TESTS}

The antioxidant activity can be evaluated by different methodologies. The DPPH radical is widely used to evaluate the ability of sequestering substances used in cosmetic and pharmaceutical formulations. This method is based on the reduction of alcoholic solutions of DPPH radical in the presence of a hydrogen donor antioxidant. It also allows lipophilic and hydrophilic test substances, i.e. independent of the polarity of substrate. However, there are antioxidants which react with the particular form DPPH * resulting in a different kinetics. We can cite compounds which react slowly, such as BHT and BHA, the compounds of the rapid kinetics, which take a few seconds, such as ascorbic acid and isogenol, and the intermediate kinetics, with reactions between 5 and 30 minutes, such as $\alpha$-tocopherol and rosmarinic acid. ${ }^{59}$
An example of another method used to evaluate the antioxidant activity of substances is the method of $\beta$-carotene, which is based on the loss of yellow color of $\beta$-carotene due to the attack of radicals formed by oxidation of linoleic acid in emulsion. The antioxidant activity by this method may be particularly useful in the investigation of lipophilic antioxidants such as essential oils. On the other hand, if the polar compounds are tested only by the $\beta$-carotene method can have the risk of underestimate the antioxidant activity of these compounds. Thus, the use of other methods is needed, such as the DPPH that is independent of the polarity of the substrate. ${ }^{59}$

Other methods based on the use of radical species and different reaction media are described in the literature, such as ABTS, ORAC (Absorption Capacity of Oxygen Radicals using Fluorescein as a Fluorescent Marker), FRAP (Total Antioxidant Activity in Ferric Reducing Antioxidant Power) and the CUPRAC assay. ${ }^{75-78}$ The use of multiple in vitro assays allows having antioxidant activity spectrum of a particular compound. Therefore, currently the description of the antioxidant potential of compounds through the use of a greater variety of in vitro assays is recommended.

\section{POTENTIAL BENEFITS FOR SKIN PROVEN BY IN VIVO TESTS}

There were many studies that identify, through in vitro methodologies, the potential benefits of antioxidants for skin, however, there is little data reporting to its functions in experimental models contemplatives of methodologies in vivo.

Regarding animal models, Sevin et al. (2007) ${ }^{79}$ show protective effect against damage caused by UVA radiation when formulation provided of vegetable extracts enriched of polyphenolic compounds was administered to rats. Kitagawa et al. (2011) ${ }^{80}$ also demonstrated preventive potential against erythematous process when formulation provided of antioxidant compounds was applied topically.

In experimental models with humans, Martorana et al. $(2013)^{81}$ identified potential anti-erythematous of pistachio extract (Pistachio Nut). Ruszova et al. (2013) ${ }^{73}$ have shown photoprotective action, in vivo, employing formulation provided of E. angustifolium extract.

Clinical trial with 15 volunteers was conducted aiming to recognize the photoprotective property consisting of resveratrol formulation. In this model, Li et al. (2009) ${ }^{82}$ demonstrated potential protective effect against repeated exposure to UV radiation.

Gianete, Mercurio and Campos $(2013)^{83}$ evaluated anti-aging effect of cosmetic preparations provided of green tea on a panel of 24 volunteers treated for up to 30 days. The authors showed improvement in parameters of hydration and micro-relief of the skin with improvement of the roughness and a gain of skin elasticity.

Investigations related to oral use associated with topical application of products provided extracts rich in antioxidants also present interesting results in biometric and histological tests. Chiu et al (2005) $)^{84}$ assessed, in a clinical study, the effect of oral supplementation associated with topical products constituted of polyphenolic compounds, in a panel consisting of 40 volunteers. The results indicated improvement of tensile property of the skin and anti-aging action. 
Clinical trials with oral supplements enriched with polyphenolic compounds show beneficial effect of this practice with decrease of wrinkle, increased of hydration and elasticity of skin..$^{85,86}$

The use of delivery systems, such as beta-cyclodextrins, to promote the increase of active permeation also proved to be an interesting strategy when the subject is the anti-aging benefit. Moyano-Mendes et al. (2014) ${ }^{87}$ have shown potential anti-aging effect of this system demonstrating the increase of skin elasticity. $\square$

\section{REFERENCES}

1. Fluhr JW, Sassning S, Lademann O, Darvin ME, Schanzer S, Kramer A, et al. In vivo skin treatment with tissue-tolerable plasma influences skin physiology and antioxidant profile in human stratum corneum. Exp Dermatol. 2012;21:130-4.

2. Staroňová K, Nielsen JB, Roursgaard M, Knudsen LE. Transport of SiO2 Nanoparticles through Human Skin. Basic Clin Pharmacol Toxicol. 2012;111:142-4.

3. Jennemann R. Loss of ceramide synthase 3 causes lethal skin barrier disruption. Hum Mol Genet. 2012;21:586-608.

4. Addor FAZ, Aoki V. Barreira cutânea na dermatite atópica. An Bras Dermatol. 2010;85:184-94

5. Cheng Y. Protection Effect of Cosmetics on Human Skin Under Simulated Rigorous Environment. Skin Res Technol. 2008;14:45-52.

6. Cravello B, Ferri A. Relationships between skin properties and environmental parameters. Skin Res Technol. 2008;14:180-6.

7. Egawa M. Effect of exposure of skin to a dry environment. Skin Res Technol. 2002:8:212-8.

8. Stevens A, Lowe J. Pele e glândula mamária. In: Histologia humana. 2. ed. São Paulo: Editora Manole; 2001. p. 355- 360

9. Dzubow L. Envelhecimento facial. In: Coleman WP, Hanke CW, Alt TH, Asken S. Cirurgia cosmética: princípios e técnicas. 2. ed. Rio de Janeiro: Revinter; 2001. p. 7-17.

10. Giacomoni PU, Rein G. A mechanistic model of the aging of human skin. Micron. 2004;35:179-84

11. Wei Y. Identification of Estrogenassociated Intrinsic Aging Genes in Chinese Han Female Skin by cDNA Microarray Technology. Biomed Environ Sci. 2011;24:364-73.

12. Piérard GE. From skin microrelief to wrinkle: an area ripe for investigation. J Cosmet Dermatol. 2003 Jan;2:21-8.

13. Velasco MVR. Rejuvenescimento da pele por peeling químico: enfoque no peeling de fenol. An Bras Dermatol. 2004;79:91-9.

14. Linder J. Cosmeceutical Treatment of the Aging Face. Aesthetic Medicine. 2011; 2: 69-84.

15. Fox LT, Gerber M, du Preez JL, Grobler A, du Plessis J.. Topical and Transdermal Delivery of L-Carnitine. Skin Pharmacol Physiol. 2011;24:330-6.

16. Wulf HC, Sandby-Møller J, Kobayasi T, Gniadecki R. Skin aging and natural photoprotection. Micron. 2004;35:185-91.

17. Taniguchi M, Arai N, Kohno K, Ushio S, Fukuda S. Anti-oxidative and anti-aging activities of 2-0- $\alpha$-glucopyranosyl-L-ascorbic acid on human dermal fibroblasts. Eur J Pharmacol. 2012 Jan 15;674:126-31

18. Tzaphlidou M. The role of collagen and elastin in age skin: an image processing approach. Micron. 2004;35:173-7.

19. Lee KK, Cho JJ, Park EJ, Choi JD. Anti-elastase and anti-hyaluronidase of phenolic substance from Areca catechu as a new anti-ageing agent. Int J Cosmet Sci. 2001:23:341-6.

20. Gniadecka M, Nielsen OF, Wessel S, Heidenheim M, Christensen DH, Wulf HC. Water and protein structure in photoaged and chronically aged skin. J Invest Dermatol. 1998;111:1129-33.

\section{ACKNOWLEDGMENT}

The authors thank the Fundação de Amparo à Pesquisa do Estado de São Paulo (FAPESP/2013-01118-5) and Conselho Nacional de Desenvolvimento Científico e Tecnológico (CNPQ) for the financial support.
21. Chorilli M, Leonardi GR, Salgado HRN. Free radicals and antioxidant agents: concepts to application in pharmaceutical and cosmetic formulations. Rev Bras Farm. 2007;88:113-118.

22. Leonardi GR, Spers VRE. Cosmetologia e Empreendedorismo: Perspectivas criação novos negócios. São Paulo: Pharmabooks; 2015.

23. Monteiro e Silva SA, Souza JG, Sper OS, Dias K, Couto R0, Lopez RFV, et al. Passive and lontophoretic Permeation and Retention Study of Gel Containing Gallic Acid and Residual Antioxidant Activity. Oral Apresentation. IFSCC Conference. Boosting Cosmetic Science in Rio; 30 Oct- 1 Nov 2013.

24. Nelson DL, Cox MM. Lehninger Principles of Biochemistry. 6th ed. New York: Freemman W. H Company; 2012.

25. Löf D, Schillén $K$, Nilsson L. Flavonoids: precipitation kinetics and interaction with surfactant micelles. J Food Sci. 2011;76:N35-9.

26. Ribeiro ME, Vieira IG, Cavalcante IM, Ricardo NM, Attwood D, Yeates SG, et al. Solubilisation of griseofulvin, quercetin and rutin in micellar formulations of triblock copolymers. Int J Pharm. 2009;378:211-4.

27. Di Mambro VM, Fonseca MJ. Assays of physical stability and antioxidant activity of a topical formulation added with different plant extracts. J Pharm Biomed Anal. 2005;37:287-95.

28. Otto A, du Plessis J, Wiechers JW. Formulation effects of topical emulsions on transdermal and dermal delivery. Int J Cosmet Sci. 2009;31:1-19.

29. Porter WL. Paradoxical behavior of antioxidants in food and biological systems. Toxicol Ind Health. 1993:9:93-122.

30. Di Mattia CD, Sacchetti G, Mastrocola D, Sarker DK, Pittia P. Surface properties of phenolic compounds and their influence on the dispersion degree and oxidative stability of olive oil 0/W emulsions. Food Hydrocoll. 2010;24:652-8.

31. Suwannalert P. Anti-Aging Activity and Non-Toxic Dose of Phytooxyresveratrol from Artocarpus lakoocha Roxb. Trop J Pharm Res. 2012;11:69-74.

32. Sugimoto S, Nakamura S, Yamamoto S, Yamashita C, Oda Y, Matsuda H, et al. Brazilian Natural Medicines. Chem Pharm Bull (Tokyo). 2009;57:257-61.

33. Guaratini T, Medeiros MHG, Colepicolo P. Antioxidantes na manutenção do equilíbrio redox cutâneo: uso e avalição de sua eficácia. Quim Nova. 2007;30:206-13

34. Ratnam DV. Role of antioxidants in prophylaxis and therapy: a pharmaceutical perspective. J Control Release. 2006;113:189-207.

35. Alleman IB, Baumann LS. Antioxidants used in skin care formulations. Skin Therapy Lett. 2008:13:5-8.

36. Mukherjee PK, Maity N, Nema NK, Sarkar BK. Bioactive compounds from natural resources against skin aging. Phytomedicine. 2011;19:64-73.

37. Barreiros ALBS, David JM, David JP. Estresse oxidativo: relação entre geração de espécies reativas e defesa do organismo. Quím Nova. 2006; 29:113-23.

38. Pinnel SR. Cutaneous, photodamage, oxidative stress and topical antioxidante protection. J Am Acad Dermatol. 2003;48:1-19.

39. Zorzi GK. Nanoemulsões contendo solução extrativa de Achyrocline sautreoides: formulação, permeação cutânea e atividade antioxidante. [dissertação]. Porto 
Alegre (RS): Universidade Federal do Rio Grande do Sul; 2007.

40. Valenti D, Manente GA, Moro L, Marra E, Vacca RA. Deficit of complex I activity in human skin fibroblasts with chromosome 21 trisomy and overproduction of reactive oxygen species by mitochondria: involvement of CAMP/PKA signaling pathway. Biochem J. 2011;435:679-88.

41. Circu ML, Aw TY. Reactive oxygen species, cellular redox systems and apoptosis. Free Radic Biol Med. 2010;48:749-62.

42. Bokov A, Chaudhuri A, Richardson $A$. The role of oxidative damage and stress in aging. Mech Ageing Dev. 2004;125:811-26.

43. Marks DB. Basic medical biochemistry: a clinical approach. Baltimore: Lippincott Williams \& Wilkins; 1996.

44. Bayir, H. Reactive oxygen species. Crit Care Med. 2005;33:S498-501.44. Ichihashi M, Ueda M, Budiyanto A, Bito T, Oka M, Fukunaga M, et al. UV-induced skin damage. Toxicology. 2003;189:21-39.

45. Valko $M$. Free radicals and antioxidants in normal physiological functions and human disease. Int J Biochem Cell Biol. 2007;39:44-84.

46. Kohen R. Skin antioxidants: their role in aging and in oxidative stress - new approaches for their evaluation. Biomed Pharmacother. 1999;53:181-92.

47. Benita S. Prevention of topical and ocular oxidative stress by positively charged submicron emulsion. Biomed Pharmacother. 1999;53:193-206.

48. El-Domyati M, Attia S, Saleh F, Brown D, Birk DE, Gasparro F, et al. Intrinsic aging vs. photoaging: a comparative histopathological, immunohistochemical, and ultrastructural study of skin. Exp Dermatol. 2002;11:398-405.

49. Nascimento LV. Avaliação e classificação do envelhecimento cutâneo. In: Kede, MPV; Sabatovich 0. Dermatologia estética. São Paulo: Atheneu; 2004. p. 45-48.

50. Shapiro SS, Saliou C. Role of vitamins in skin care. Nutrition. 2001;17:839-44.

51. Biesalski HK, Obermueller-Jevic UC. UV light, beta-carotene and human skinbeneficial and potentially harmful effects. Arch Biochem Biophys. 2001;389:1-6.

52. Fisher GJ, Kang S, Varani J, Bata-Csorgo Z, Wan Y, Datta S, et al. Mechanisms of photoaging and chronological skin aging. Arch Dermatol. 2002;138:1462-70.

53. Longstreth J, de Gruijl FR, Kripke ML, Abseck S, Arnold F, Slaper HI, et al. Health risks. J Photochem Photobiol B. 1998;46:20-39.

54. Casagrande R, Georgetti SR, Verri WA Jr, Borin MF, Lopez RF, Fonseca MJ. In vitro evaluation of quercetin cutaneous absorptions from topical formulations and its functional stability by antioxidant activity. Int J Pharm. 2007;328:183-90.

55. Montagner S, Costa A. Molecular basis of photoaging. An Bras Dermatol. 2009;84:263-9.

56. Abla MJ, Banga AK. Quantification of skin penetration of antioxidants of varying lipophilicity. Int J Cosmet Sci. 2013;35:19-26.

57. Kojima S, Takai E, Tsukimoto M. ATP Released from Low-dose Gamma Rayirradiated Cells Activates Intracellular Antioxidant Systems via Purine Receptors. Anti-aging Medicine. 2011;8:108-13.

58. Soares M. Evaluation of antioxidant activity and identification of phenolic acids present in the pomace of Gala variety apples. Ciênc Tecnol Aliment. 2008;28:727-32.

59. Carpes ST, Prado A, Moreno IAM, Mourão GB,Alencar SM, Masson ML. Avaliação do potencial antioxidante do pólen apícolaproduzido na região Sul do Brasil. Quím Nova. 2008;31:1660-4.

60. Namiki M. Antioxidants/antimutagens in food. Crit. Crit Rev Food Sci Nutr. 1990;29:273-300.

61. Wickens AP. Ageing and the free radical theory. Respir Physiol. 2001;128:379-91.

62. Podda M, Grundmann-Kollmann M. Low molecular weight antioxidants and their role in skin ageing. Clin Exp Dermatol. 2001;26:578-82.

63. Jay V, Berthon JY, Hagege P, Pouget MP, Lejeune B, Pourrat H. New Active Ingredient for Aging Prevention. Cosm Toiletries. 1998;113:71-7.

64. Kohen R. Skin antioxidants: their role in aging and in oxidative stress - new approaches for their evaluation. Biomed Pharmacother. 1999;53:181-92.

65. Bagatin E. Envelhecimento cutâneo e o papel dos cosmecêuticos. Boletim Dermatológico UNIFESP. 2008;17:1-4.

66. Heim KE, Tagliaferro AR, Bobilya DJ. Flavonoid antioxidants: chemistry, metabolism and structure-activity relationships. J Nutr Biochem. 2002;13:572-584

67. Hammerstone JF, Lazarus SA, Mitchell AE, Rucker R, Schmitz HH. Identification of procyanidins in cocoa (Theobroma cacao) and chocolate using High-performance Liquid Chromatography/Mass Spectrometry. J Agric Food Chem. 1999;47:490-6.

68. Angelo PM, Jorge N. Compostos fenólicos em alimentos - Uma breve revisão. Rev. Inst. Adolfo Lutz. 2007;66:1-9.

69. Thring TSA, Hili P, Naughton DP. Antioxidant and potential anti- inflammatory activity of extracts and formulations of white tea, rose, and witch hazel on primary human dermal fibroblast cells. J Inflamm (Lond). 2011;8:27.

70. Lee KK, Cho JJ, Park EJ, Choi JD. Anti-elastase and anti-hyaluronidase of phenolic substance from Areca catechu as a new anti-ageing agent. Int J Cosmet Sci. 2001;23:341-6.
71. Kim JE, Shin MH, Chung JH. Epigallocatechin- 3-gallate prevents heat shockinduced MMP-1 expression by inhibiting AP-1 activity in human dermal fibroblasts. Arch Dermatol Res. 2013;305:595-602.

72. Stevanato R, Bertelle M, Fabris S. Photoprotective characteristics of natural antioxidant polyphenols. Regul Toxicol Pharmacol. 2014;69:71-7.

73. Ruszová E, Cheel J, Pávek S, Moravcová M, Hermannová M, Matějková I, et al. Epilobium angustifolium extract demonstrates multiple effects on dermal fibroblasts in vitro and skin photo-protection in vivo. Gen Physiol Biophys. 2013;32:347-59.

74. Giampieri F, Alvarez-Suarez JM, Mazzoni L, Forbes-Hernandez TY, Gasparrini M, Gonzàlez-Paramàs AM, et al. Polyphenol-rich strawberry extract protects human dermal fibroblasts against hydrogen peroxide oxidative damage and improves mitochondrial functionality. Molecules. 2014;19:7798-816.

75. Zampini IC, Ordoñez RM, Isla MI. Autographic Assay for the Rapid Detection of Antioxidant Capacity of Liquid and Semi-solid Pharmaceutical Formulations Using ABTS+ Immobilized by Gel Entrapment. AAPS PharmSciTech. 2010;11:1159-63.

76. Kukic J. Antioxidant and antimicrobial activity of Cynara cardunculus extracts. Food Chem. 2008;107:861-8.

77. Ou B, Hampsch-Woodill M, Prior RL. Development and Validation of an Improved Oxygen Radical Absorbance Capacity Assay Using Fluorescein as the Fluorescent Probe. J Agric Food Chem. 2001;49:4619-26.

78. Lopes LB, VanDeWall H, Li HT, Venugopal V, Li HK, Naydin S, et al. Topical Delivery of Lycopene Using Microemulsions: Enhanced Skin Penetration and Tissue Antioxidant Activity. J Pharm Sci. 2010;99:1346-57.

79. Sevin A, Oztaş P, Senen D, Han U, Karaman C, Tarimci N, et al. Effects of polyphenols on skin damage due to ultraviolet $A$ rays: an experimental study on rats. J Eur Acad Dermatol Venereol. 2007;21:650-6.

80. Kitagawa S, Yoshii K, Morita SY, Teraoka R. Efficient topical delivery of chlorogenic acid by an oil-in-water microemulsion to protect skin against UV-induced damage. Chem Pharm Bull (Tokyo). 2011;59:793-6.

81. Martorana M, Arcoraci T, Rizza L, Cristani M, Bonina FP, Saija A, et al. In vitro antioxidant and in vivo photoprotective effect of pistachio (Pistacia vera L., variety Bronte) seed and skin extracts. Fitoterapia. 2013;85:41-8.

82. Li YH, Wu Y, Wei HC, Xu YY, Jia LL, Chen J, et al. Protective effects of green tea extracts on photoaging and photommunosuppression. Skin Res Technol. 2009;15:338-45.

83. Gianeti MD, Mercurio DG, Campos PM. The use of green tea extract in cosmetic formulations: not only an antioxidant active ingredient. Dermatol Ther. 2013;26:267-71.

84. Chiu AE, Chan JL, Kern DG, Kohler S, Rehmus WE, Kimball AB. Double- blinded, placebo-controlled trial of green tea extracts in the clinical and histologic appearance of photoaging skin. Dermatol Surg. 2005;31:855-60

85. Buonocore D, Lazzeretti A, Tocabens P, Nobile V, Cestone E, Santin G, et al. Resveratrol-procyanidin blend: nutraceutical and antiaging efficacy evaluated in a placebocontrolled, double-blind study. Clin Cosmet Investig Dermatol. 2012;5:159-65.

86. Udompataikul M, Sripiroj P, Palungwachira P. An oral nutraceutical containing antioxidants, minerals and glycosaminoglycans improves skin roughness and fine wrinkles. Int J Cosmet Sci. 2009;31:427-35.

87. Moyano-Mendez JR, Fabbrocini G, De Stefano D, Mazzella C, Mayol L, Scognamiglio I, et al. Enhanced antioxidant effect of trans-resveratrol: potential of binary systems with polyethylene glycol and cyclodextrin. Drug Dev Ind Pharm. 2014;40:1300-7.

\section{MAILING ADDRESS: \\ Gislaine Ricci Leonardi \\ Universidade Estadual de Campinas \\ Rua Cândido Portinari, 200 \\ 13083-871 - Campinas - SP - Brazil \\ E-mail: grleonardi@hotmail.com}

How to cite this article: Monteiro e Silva SA, Michniak-Kohn B, Leonardi GR. An overview about oxidation in clinical practice of skin aging. An Bras Dermatol. 2017;92(3):367-74. 